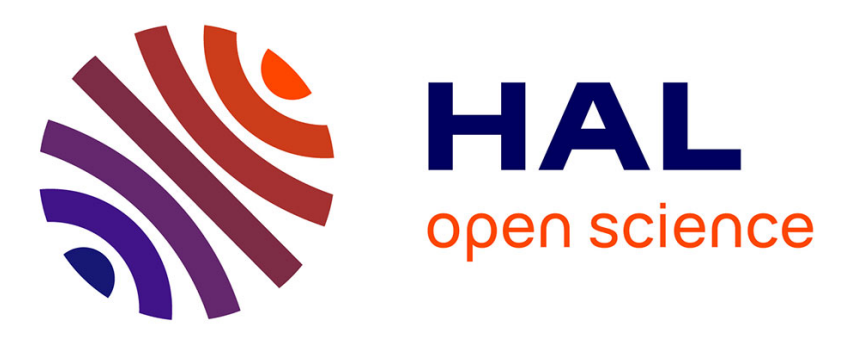

\title{
Statistical fracture of E-glass fibres using a bundle tensile test and acoustic emission monitoring
}

Mohamed R'Mili, M. Moevus, Nathalie Godin

\section{To cite this version:}

Mohamed R'Mili, M. Moevus, Nathalie Godin. Statistical fracture of E-glass fibres using a bundle tensile test and acoustic emission monitoring. Composites Science and Technology, 2009, 68 (7-8), pp.1800. 10.1016/j.compscitech.2008.01.018 . hal-00563499

\section{HAL Id: hal-00563499 \\ https://hal.science/hal-00563499}

Submitted on 6 Feb 2011

HAL is a multi-disciplinary open access archive for the deposit and dissemination of scientific research documents, whether they are published or not. The documents may come from teaching and research institutions in France or abroad, or from public or private research centers.
L'archive ouverte pluridisciplinaire HAL, est destinée au dépôt et à la diffusion de documents scientifiques de niveau recherche, publiés ou non, émanant des établissements d'enseignement et de recherche français ou étrangers, des laboratoires publics ou privés. 


\section{Accepted Manuscript}

Statistical fracture of E-glass fibres using a bundle tensile test and acoustic emission monitoring

M. R'Mili, M. Moevus, N. Godin

PII:

S0266-3538(08)00029-8

DOI:

10.1016/j.compscitech.2008.01.018

Reference:

CSTE 3954

To appear in:

Composites Science and Technology

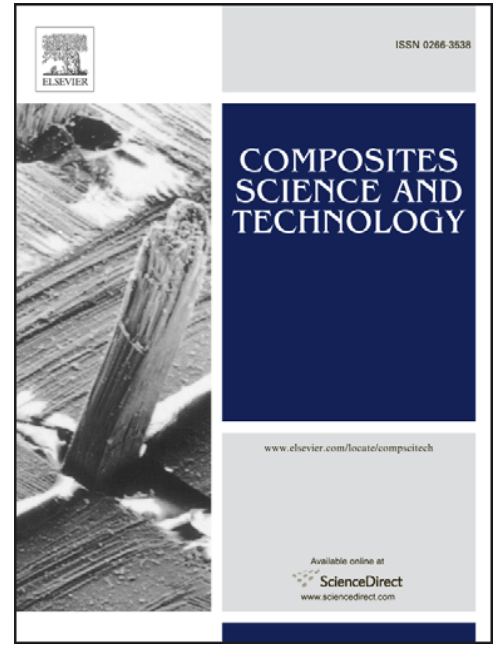

Received Date: $\quad 22$ September 2005

Revised Date: $\quad 2$ August 2007

Accepted Date: $\quad 29$ January 2008

Please cite this article as: R'Mili, M., Moevus, M., Godin, N., Statistical fracture of E-glass fibres using a bundle tensile test and acoustic emission monitoring, Composites Science and Technology (2008), doi: 10.1016/ j.compscitech.2008.01.018

This is a PDF file of an unedited manuscript that has been accepted for publication. As a service to our customers we are providing this early version of the manuscript. The manuscript will undergo copyediting, typesetting, and review of the resulting proof before it is published in its final form. Please note that during the production process errors may be discovered which could affect the content, and all legal disclaimers that apply to the journal pertain. 


\title{
Statistical fracture of E-glass fibres using a bundle tensile test and acoustic emission monitoring
}

\author{
M. R'Mili ${ }^{*}$, M. Moevus, N. Godin \\ Université de Lyon, INSA-Lyon, MATEIS, 7 Avenue Jean Capelle, 69621 Villeurbanne Cedex, France \\ * Corresponding author: Mohamed.Rmili@insa-lyon.fr
}

\begin{abstract}
Mechanical strength studies have been carried out on fibre bundles used in composite manufacturing. The variability in mechanical properties of glass fibres has been studied using bundles of about 2000 filaments. The fibre strength distributions were analysed using the survival probability-applied strain $(S-\varepsilon)$ curve, in relation with various experimental conditions. We also examine the effect of lubricant's viscosity on the fracture behaviour of Eglass fibre bundles. Acoustic Emission (AE) was monitored during the bundle tensile tests in order to verify that individual filament failures are statistically independent. On tensile tests with lubricated bundles of E-glass fibres, it is shown that each individual fibre break can be detected using AE. Hence, AE monitoring of a lubricated bundle of E-glass fibres provides a convenient and relatively quick method to obtain the Weibull parameters of strength distribution.
\end{abstract}

Keywords: A. E-glass fibres; A. Bundle tensile test; B. Sub-critical crack growth; B. moisture effect; C. Statistical fracture; C. Weibull distribution; D. Acoustic emission.

\section{Introduction}

The strength of unidirectional composites is essentially dependent on the mechanical behaviour of their reinforcement. The evaluation of this mechanical property requires knowledge of the mechanical characteristics of the fibres. It has been shown that the variability of the tensile properties of fibres can be obtained by single fibre testing [1-3] or by Bundle Tensile Test 
(BTT) technique. The fibre bundle models with equal load sharing rule were originally introduced by Daniels [4] and Coleman [5]. The fibre bundle models are based on parallel set of fibres each of which has Weibull distribution function [6]. Phoenix [7-9] gave a theoretical review of probabilistic models for fibre bundles. In its approach the classical equal load sharing model appears as a special case of generalised models where the load on each surviving fibre is not necessary the same. These generalised models extended to case of elastic fibre bundles with random fibre slack, and also to the case of hybrid bundles with several types of fibres. Using the most common single fibre test technique, it is possible to characterise the strength distribution of the fibres if a large number of individual fibre $(n \geq 40)$ are tested, and thus to estimate the parameters of the associated Weibull strength distribution. However, some uncertainties appear on the determination of the parameters of the strength distribution by this method. The specimen selection and damage of the fibres during the sampling operation are some problems introducing errors on the determination of Weibull parameters. The bundle tensile test technique allows us to overcome some of these problems. Hence it becomes an alternative method to obtain the strength distribution of the fibres [10-19] and has been used with successfully to study the coating effect on strength distribution changes of carbon fibres [20,21]. The only difficulty is to obtain a reliable load-strain $(P-\varepsilon)$ curve of the bundle under quasi-static loading. The determination of the bundle elongation during the test is also a problem because it is generally deduced from the displacement of the crosshead of the testing machine.

It must be emphasized, that in BTT the major difficulties are the specimen preparation and the strain measurement during the tensile test. Variation in fibre cross-sectional area may not be important on a bundle test, but in matters in composite with matrix that affects the local load sharing and the transfer of the load intensity between surviving fibres. In fact, the magnitude of transfer load depends on the fibre radius. Whereas, the analysis on the bundle test, conducted 
with a reliable measurement of the true deformation, allows to overcoming the problems linked to the variation of the cross-sectional area of the fibres like the scattering of ultimate stresses which is linked to the accurate measurement of the cross-sectional area of the fibres. The large number of broken fibres and the measurement of the true deformation during the bundle test give the accurate information about the fracture behaviour of fibres.

The failure of bundles of E-glass fibre has been monitored using load-strain measurements and acoustic emission (AE). AE technique is a non-destructive method at damage evaluation [2224], that uses stress waves emitted by stressed material undergoing deformation processes as plastic deformation or crack growth. As an elastic wave or AE signal travels through a material, its characteristics are constantly changing due to damping, boundary surface interactions, etc. Hence a wave form recorded by an AE device is a transformed representation of the wave created by the AE source. In conventional acoustic emission testing, the elastic wave produced by a source is converted to a voltage signal by a resonant piezo-electric sensor. The AE technique has been used in this study to detect fibre breaks on a one - to - one basis and to determine the variability of the fibre breaks in relation with the $(P-\varepsilon)$ analysis. Also Phoenix et al. [24] and Hamstad et al. [25] have used silicone-oil lubricant to reduce the friction between the fibres on Kevlar bundles. They found that all the breaks could be detected and counted individually. Same results were reported in the literature, but in these cases it was be difficult to use BTT in order to obtain the fracture stress distributions of fibres. Only the first part of the load-strain curve below maximum was considered in order to obtain fibres properties. Some works [26-29] investigates also the discrepancy between experimental data and theory on the tensile behaviour and strength of fibres bundle.

In the present study, experiments were conducted on lubricated fibres bundles. Due to the lubrication, multiple fractures at fibres are expected to be reduced by lowering the interactions between the individual filaments. In addition, the lubricant is used as coupling to 
obtain a better propagation of acoustic waves. The aim of the present study was to use $\mathrm{AE}$ technique to detect fibre failures in a bundle, in order to validate the mechanical BTT. So the tests have been performed on E-glass fibres bundles with about $204 \times 10$ filaments. AE data will allow us to better understand of the fracture mechanisms of the bundle during tensile test. The fibre strength distributions are analysed with two different methods (using $(P-\varepsilon)$ and $\mathrm{AE}$ analysis). Weibull diagram plots were derived from the load applied strain curve and AE eventstrain data. Moreover, the effects of the test conditions on the BTT are investigated: effect of the lubricants viscosity and effect at moisture conditions on the fracture behaviour of the Eglass fibre. For the last point, Brown [30] showed that the strength, the number of fibre breaks at the peak load and Weibull parameters are strongly dependent on the humidity level of the Eglass fibre. Phoenix et al. [24] showed that the Kevlar fibres are more sensitive to the UV light exposure.

\section{Theoretical background}

\section{1. Bundle model}

The theoretical model of dry bundle fibre consists in a set of $N_{o}$ parallel fibres with statistically distributed strength. The sample is loaded parallel to fibres direction and the fibres fail if the load on them exceeds their threshold value. In stress controlled experiments, after each fibre failure the load carried by the broken fibre failure is redistributed among the unbroken ones following an equal load-sharing rule. This means that after each fibre break the stress is equally distributed on the surviving fibres assuming that no interaction acts between the broken fibres and their neighbours. The high variability in strength found in brittle fibres is well modelled by Weibull function. This variability is due to randomly distributed flaws on the fibres. The assumptions generally used in this analysis, so-called Coleman's conditions are: 1) filament 
length is constant within the bundle, 2) the stress-strain relationship for a single fibre follows the Hooke's law up to failure, 3) load released with the fracture of one fibre is uniformly distributed among the surviving fibres, 4) absence of phenomena which will be able to a premature failure of fibres.

This last point is very important. Then, up to the maximum of load, the dry bundle model and the experimental data are in good agreement. On the contrary, just after the peak load, the experimental load-strain curve exhibit catastrophic failure with a large magnitude of load drop that was not predicted by the theoretical model. This difference is certainly due to fibres interactions as friction between the fibres, stress concentration near the ends of the bundle. Therefore specific cares are taken to reduce these effects and to obtain experimental curves in better accordance with the model.

\section{2. Statistical distribution of fibre strength: Single Weibull distribution}

Using BTT, the properties of fibres are generally described in terms of the strain $\varepsilon$ rather than in terms of the stress $\sigma$. These two descriptions are equivalent, as for ceramic fibres, the applied stress $\sigma$ and strain $\varepsilon$ follow Hooke's law up to failure:

$\sigma=E_{f} \mathcal{E}$

where $E_{f}$ is the fibre Young's modulus.

The bundle test is then also likely to give the two Weibull parameters of perfect elastic fibres using a $(P-\varepsilon)$ curve. The bundle theory has been used by Chi and al. [8] to assimilate the strengths of loose bundle of carbon fibre with those of single carbon fibres. Chi and al. showed that the behaviour of bundles can be described from the simple Weibull strength distribution of fibres and from their geometrical characteristics. Indeed, for a large number of fibres, the number of survival fibres at an applied strain, $\varepsilon$ is given by: 
$N(\varepsilon)=N_{o} \exp \left[-\left(\frac{\varepsilon}{\varepsilon_{l}}\right)^{m}\right]$

where $\varepsilon_{l}$ is a scale parameter for a given gauge length $l$ and $m$ is the Weibull modulus, and $N_{o}$ is the number of initially loaded fibres. The survival probability of fibres, $S(\varepsilon)$, corresponding to the number $N(\varepsilon)$ of fibres that survive at a given strain $\varepsilon$ divided by the initial number of loaded fibres $N_{o}$, can be expressed as:

$S(\varepsilon)=\frac{N(\varepsilon)}{N_{o}}=\exp \left[-\left(\frac{\varepsilon}{\varepsilon_{l}}\right)^{m}\right]$

A commonly used approach relies on least-squares fit of a linear form of Eq. (3).

$\operatorname{Ln}[-\operatorname{LnS}(\varepsilon)]=m \operatorname{Ln} \mathcal{\varepsilon}-\operatorname{Ln} \varepsilon_{l}$

which is a linear equation with slope $m$. It is easy to see from Eq. (3) that $\varepsilon_{l}$ is the strain corresponding to a survival probability of $1 / \mathrm{e}$ or 0.37 .

Assuming that the applied load is uniformly distributed among the surviving fibres and that fibres have a linear load-strain relationship up to breakage, the load at an applied strain $\varepsilon$ during a bundle tensile test is given by:

$P=c A N(\varepsilon)=E_{f} \varepsilon A N(\varepsilon)=N_{o} A E_{f} \varepsilon S(\varepsilon)$

where $\mathrm{A}$ is the cross-sectional area of each of the fibres, $E_{f}$ their Young's modulus. The most common technique for estimating the Weibull parameters is to plot the observed data in the linear form of Eq. (4).

\section{Experimental procedure}

\subsection{Specimen preparation and investigated material}


Fibre bundle specimens were prepared according to the protocol described in a previous paper [18]. In the present study, tensile tests on bundles of 30, 60 and $100 \mathrm{~mm}$ gauge length have been performed on E-glass fibres manufactured by Vetrotex firm. The mechanical behaviour of bundles has been studied in a tension test on bundle of about $204 \times 10$ filaments. The mean fibre diameter is $15 \pm 2 \mu \mathrm{m}$ and the elastic modulus is $71 \pm 2 \mathrm{GPa}$.

\subsection{Tensile test}

All the tensile bundle tests have been carried out in room atmosphere $\left(23 \pm 2^{\circ} \mathrm{C}\right.$ and $30 \pm$ $20 \%$ of relative humidity). These tests were performed under with a pneumatic testing machine with a $250 \mathrm{~N}$ load cell. Two small thermo-retractable stumps of $3 \mathrm{~mm}$ long are threaded on the bundle to define the gauge length and to allow clamping of the mechanical extensometer with specific clamps [18]. To put and optimise the position of the extensometer, the sample is previously loaded under $15 \%$ of the ultimate load. Fig. 1 shows a view of bundle testing tab, clamping system of the extensometer and Acoustic Emission sensors. Nominal strain values were measured directly with a mechanical extensometer. The tensile tests have been performed with a crosshead speed of $2 \mu \mathrm{m} / \mathrm{s}$. To point out the effect of the humidity, several tests have been conducted after water immersion. In these cases the bundles were lubricated just prior to the loading. In order to examine the effect of lubricant oils on the fracture behaviour change, several lubricants with various viscosities were used.

\subsection{Acoustic emission system}

A two channel Mistras 2001 data acquisition system of Euro Physical Acoustics (EPA) was used for the recording of AE data. Two resonant PZT transducers (Acoustic Emission type $\mu 80$ ) were acoustically connected to the end of the samples with silicon grease. Table 1 summarizes the typical setting of the AE system. The amplitude distribution covers the range 
0-100 dB ( $0 \mathrm{~dB}$ corresponds to $1 \mu \mathrm{N}$ at the transducer output). A fixed threshold of $32 \mathrm{~dB}$ was used. This threshold allows to minimize electronic background noise due to the grips, the tensile testing machine and others electrical machines. Preliminary measurements have been performed to optimise the acquisition parameters to the case of the fibres studied (table 1). Simulated AE events with pencil lead breaks were used to verify that AE signals were well transmitted across the metallic-sample interface, and to evaluate the wave speed. Each simulated signals recorded was analysed by the Mistras system and six parameters are calculated from the waveforms: rise time, counts, energy, duration, amplitude, counts to peak. These were used for the conventional analysis of AE data. Furthermore each waveform is digitised and stored. The signals detected are also subjected to a calculation procedure to determine the location of AE signal source. During the AE data analysis, only the events located between the two sensors are considered.

\subsection{Methods of analysis}

\subsection{1. $P-\varepsilon$ curve analysis}

The experimental procedure to estimate the survival probability from the $(P-\varepsilon)$ curve was described in detail by Chi and al. [11] for a single Weibull distribution. Eq. (5) can be expressed as: $P=N_{o} A E_{f} \varepsilon S(\varepsilon)=\Re_{o} \varepsilon S(\varepsilon)$

and

$\Re_{o}=\left.\frac{d P}{d \varepsilon}\right|_{\varepsilon=0}=A E_{f} N_{o}$

where $\Re_{o}$ is the initial slope of $(P-\varepsilon)$ curve.

It is observed from Eq. (6) that the survival probability of the fibres is given by:

$S(\varepsilon)=\frac{\Re(\varepsilon)}{\Re_{0}}$ 
where $\mathfrak{R}(\varepsilon)=\mathrm{P} / \varepsilon$ is the slope of the straight line connecting the origin and the current point of $(P-\varepsilon)$ curve. Thus the survival probability $S(\varepsilon)$, at any strain level $\varepsilon$, can be determined experimentally from the $(P-\varepsilon)$ curve using Eq. (8). This method allows us to overcome the characteristics of the bundle like: Young's modulus $\left(E_{f}\right)$, the initial number $\left(N_{0}\right)$ and individual cross-section area of fibres $(A)$. A schematic describing determination of $\Re_{\mathrm{o}}$ and $\mathfrak{R}(\varepsilon)$ from experimental $(P-\varepsilon)$ curve is given Fig. 2 .

\subsection{2. $S-\varepsilon$ curve analysis}

The $(P-\varepsilon)$ curves are dependent on bundle characteristics, essentially of initial number of fibres and cross section. The survival probability function is independent of fibres Young's modulus, of the initial number and of the individual cross-section area of fibres (Eq. 3). Therefore, the $(S-\varepsilon)$ can be regarded as a master curve and can be used as an indicator of the evolution of mechanical properties of the fibres in a given experimental conditions. Thus in this study, we chose to use $(S-\mathcal{E})$ diagrams to analyse our experimental data. In the present work, for estimating Weibull parameters, a non-linear least squares method is applied using a non-linear curve fitting Eq. (3). We used the chi-square test $\left(\chi^{2}\right)$ to evaluate the accuracy of curve fitting. The results are compared with those obtained by linear fit method Eq. (4).

\section{Results and discussion}

\subsection{Validation of experimental measurements}

\subsubsection{Influence of the lubrication}

In order to examine the effect of the lubricant oils viscosity on the fracture change of Eglass bundles, several lubricants were used. Viscosity versus shear rate for various lubricant oils is shown in Fig. 3. Typical load-strain curves obtained with a dry bundle (1), petrol oil (2), 
vaseline oil (3) and light-oil lubricant (4) are given in Fig. 4. This figure shows that the fracture of fibre is linked to the lubricant viscosities. The maximum of load and the corresponding strain are significantly reduced in the dry bundle. On the other hand, a significant increase in the stress and the corresponding strain is obtained with light-oil lubricant. It is clear that for the highest viscosity (vaseline oil) a decrease of the mechanical properties is observed. As the lubricant viscosity increases, the lateral interaction of the fibre in a bundle enhances local load sharing and thus contributes to the premature fracture of the neighbouring fibres. Hence, it can observe that dry bundles (1) lead to the premature and unstable fracture in comparison with the lubricated bundles. This phenomenon is due to damage induced by inter fibres friction [15], and by a dynamic failure during the breaking process [11]. When a fibre fails, it retracts that induces a relative displacement with respect to the neighbours. Through shearing the viscous medium that will induce slight tensile overloads on the nearest neighbours. Fig. 5 shows the appearance difference of bundles between a dry and lubricated one. After the test, the dry bundle has the appearance of a cotton-wool, as observed by some authors $[12,15]$. For the lightoil lubricant, the fracture is stable indicating that the lubricant reduces the friction damage and the premature fracture by dynamic effect. Indeed, during the fracture process of the bundle with lubricant oil, the fibre remains certainly in their initial position without interaction with neighbouring fibres. It is clear that the efficiency of the lubrication depend on the inter-fibres spacing, the fibres diameters distribution and the wet-ability of the lubricant. For the next, all the tests are performed with the light-oil lubricant.

\subsubsection{Loading - unloading test}

The necessary condition required to obtain $S(\varepsilon)$ with a good accuracy, is that during the tensile test the $(P-\varepsilon)$ curve of the bundle exhibit no residual strain when the bundle is totally unloaded before the total fracture of the bundle. It can be verified with particular tensile 
tests where an unloading-reloading cycle to as carried out after the peak load. Examples of these curves obtained with bundle of glass and carbon fibres are shown in Figs. $6 \mathrm{a}$ and $6 \mathrm{~b}$ respectively. These figures show that the $(P-\varepsilon)$ curve during the loading-unloading cycle is relatively linear, the residual displacement tends to zero and the area at the hysteresis loop is very small. This is typical of elastic damage behaviour as described in Fig. 2. For glass fibres, an important load loss (indicated by the superposed circle) is observed during the unloadingreloading sequence. This phenomenon can be attributed to sub-critical crack growth process. This is confirmed by carbon fibres that are not sensitive to stress assisted corrosion in room atmosphere. This will be discussed later.

The elastic damage behaviour of the bundle is a result of individual fracture of fibres. So the failure of each fibre is followed by a redistribution of load among all the surviving fibres which do not induce further fibre breaks in the vicinity. These remarks imply that the compliance changes are only the results of fibres fractures and the friction between the fibres can be neglected. Thus the survival probability $S(\varepsilon)$ can be experimentally measured with a good accuracy.

\subsubsection{Analysis of the acoustic emission data}

Typical mechanical and AE results are presented in Fig. 7. This figure shows the tensile load-strain curve for two gauge lengths $(30$ and $100 \mathrm{~mm})$ and linear location of AE events between the two sensors. The solid lines indicate the approximate locations of the bundle ends. Only the events localised in the length have been taken into account during the AE data analysis. The $(P-\varepsilon)$ curve presents a linear phase, which is followed by a non-linear behaviour. Moreover, the failure of bundle is stable beyond peak load. Whatever the length, the fibre break are distributed over the entire gauge length during the bundle failure. It can noticed that for the short gauge length some breaks are located, only at the beginning of the test, near 
the bundles ends due to the end effects. For larger gauge lengths, this fracture mechanism is reduced. The "end-effect" model was already discussed in details by Stoner and al. [31].

The friction between fibres is a source of additional AE that increases with the gauge length. This phenomenon is well highlighted by the histograms of amplitude distributions (see Fig. 8.). One can note the presence of two distributions. A principal distribution with amplitudes ranged from approximately 80 to $95 \mathrm{~dB}$, can be attributed to the fibre breaks. The amplitudes of the signals recorded in this distribution during the tensile test increase with the applied strain. This is due to the fact that weak fibres fail under low strain and the fibres with high strength at the end of the test. A second distribution, located towards the low amplitudes, is observed principally on the bundle with large gauge lengths. This second distribution of AE signal is low and can be allotted to the friction between fibres. For the next, this distribution is not taken into account for the statistical analysis of fibre breaks.

Fig. 9 shows the evolution of the cumulative count of AE events and the load with the applied strain for a bundle of 30 and $100 \mathrm{~mm}$ gauge length. The number of signals recorded on the bundle with gauge length of $100 \mathrm{~mm}$ is around 2000 . Hence all the fibre breaks have been detected. On the other hand for $30 \mathrm{~mm}$ gauge length, less than 2000 signals are recorded due to the end effect. To confirm that "end effect" mechanism was predominant for the short gauge length, the $(S-\varepsilon)$ curves obtained from $(P-\varepsilon)$ and AE analyses have been calculated. Fig. 10 shows that for $30 \mathrm{~mm}$ gauge length (Fig. 10a) a significant difference is observed between the survival probability obtained by using the $(P-\varepsilon)$ and AE analysis. On the contrary for 100 $\mathrm{mm}$ gauge length (Fig. 10b) the two methods give similar results. Therefore, for the short gauge length one part of fibre breaks is due to the "end effect" discussed below. In a general way, this is a good accordance between the number of acoustics events and the number of fibres fractures determined by the analysis of the $(P-\varepsilon)$ curve. Agreement of $5 \%$ was obtained (Table 2). This shows that the two techniques give similar results for fibre breaks 
especially for the large gauge lengths. The cumulative count of $\mathrm{AE}$ events and amplitude distributions show that each fibre breaks individually. The part of multiple fibre breaks is also reduced and single fibre breaks are dominant during the mechanical test. This result is in good agreement with the fact that catastrophic collapse of the bundle did not occur. Because fibre breaks occur one-by-one and are randomly distributed along the gauge length, fibre breaks are statistically independent. On the location graph, no cluster is observed. The signals assigned to the fibre breaks have higher amplitude, quick rising and decaying. This AE signature can be used to train supervised classifier in composite materials [32-34]. Nevertheless, in that case the AE signature of the fibre breaks in a matrix will be certainly different and new type of flaws and fracture mechanisms appears for composite materials.

\subsubsection{Effect of relative humidity level}

The $(S-\varepsilon)$ curves (Fig. 11) exhibit a significant change of the bundle fracture behaviour with the relative humidity (RH). Failure stresses are measured at two humidity levels $30 \% \mathrm{RH}$ and after immersion in water. The results show an important decrease of the strength between the bundles loaded in room atmosphere $(30 \% \mathrm{RH})$ and for bundles tested under water. The strength estimate at $50 \%$ of survival probability was found equal to $1.44 \mathrm{GPa}$ for dry bundle $(30 \% \mathrm{RH})$ and only $0.92 \mathrm{GPa}$ for fibres tested under water. This result points out that the moisture has a significant effect on fracture of the bundles and affects strongly the fracture behaviour and the mean strength of glass fibres. This result is attributed to the effects of stress corrosion in humid environment where flaws growth due to stress-corrosion mechanisms. It is well known that the strength of glass-fibres is sensitive to the relative humidity $[35,36]$ because in these fibres, pre-existing flaws subjected to stress and in presence of water vapour grow subcritically up to critical size leading to fibre break. This is due to the weakening of SiOSi bonds 
by water molecules, and to the stress concentration around the crack tip can leading then to the fracture of these bonds.

\subsection{Statistical analysis}

Fig.12 shows for different gauge lengths $(30,60$ and $100 \mathrm{~mm})$ the strength distribution derived from the acoustic emission analysis. In the Weibull diagram, Fig. 12 exhibits approximately a linear and small effect of gauge length changes. Usually in the Weibull plots the analysis derived from the mechanical data exhibits a pseudo bi-modal behaviour. In the present case, the apparition of non-linearity is not due to a second population of defects. But is due to the fibre breaks by the "end effects" and that can not be removed from the experimental data obtained with mechanical analysis. For the data obtained by acoustic emission analysis, the absence of non-linearity can be noticed. The use of the location procedure allows to separate "end effects" from the true fibre strength distribution. Therefore for the large gauge lengths, the fibre breaks are essentially controlled by one type of defect, certainly surface defects. The Weibull parameters were determined by the linear fit method Eq. (4) and the non linear fit method Eq. (3). The parameter values with various gauge length are summarized in table 2. Also the Weibull parameters extracted by using $(P-\varepsilon)$ analysis are reported in brackets (). As part of $30 \mathrm{~mm}$ gauge length, the results from the two methods are approximately similar. In the Weibull plot no change in observed between 60 and $100 \mathrm{~mm}$ gauge length. Consequently, for the large lengths the fracture behaviour of E-glass fibre can be described well by a two-parameter Weibull function.

\section{Conclusion}


Bundle tensile tests on E-glass fibre have been performed to failure with $\mathrm{AE}$ monitoring. The identification of fibres breaks by "end-effect" process, lubricant oil viscosity, and controlled breaks progression after the peak load, in addition to direct measurement of true strain by extensometer are key points to obtain a reliable determination of the statistical parameters of the fibre breaks. The $\mathrm{AE}$ technique gives additional information on the fibre breaks process. The linear location and the fibre breaks detection allow us to overcome the problems linked with the load-strain analysis like "end-effect". Therefore the statistical Weibull parameters can be extracted from the survival probability function-applied strain with a good accuracy.

We have demonstrated that under adequate oil lubrication condition, premature failure of fibres is significantly reduced. It is also shown that glass fibres are strongly sensitive to relative humidity level. Finally, up to $30 \mathrm{~mm}$ gauge length, the fracture behaviour of E-glass fibres appears to be principally controlled by one type of defect, attributed to surface defects.

\section{References}

[1] Wilson DM. Statistical tensile strength of Nextel ${ }^{\mathrm{TM}} 610$ and Nextel ${ }^{\mathrm{TM}} 720$ fibres. J Mater Sci 1997;32:2535-2542.

[2] Lissart N, Lamon J. Statistical analysis of failure of SiC fibers in the presence of bimodal flaw populations. J Mater Sci 1997;32:6107-6117.

[3] Lavaste V, Besson J, Bunsell AR. Statistical analysis of strength distribution of alumina based single fibres accounting for fibre diameter variation. J Mater Sci 1995;30:2042-2048.

[4] Daniels HE. The statistical theory of the strength of bundles of threads. Proc R Soc 1945;A 183:405-35.

[5] Coleman BD. On the strength of classical fibers bundle. J Mech Phys Solids 1958;7:60-70.

[6] Weibull W. A statistical distribution function of wide applicability. J Appl Mech 1951;18(3):293-7. 
[7] Phoenix SL, Taylor HM. The asymptotic strength distribution of a general fiber bundle. Adv. Appl. Prob.1973;5:200-16.

[8] Phoenix SL. Probabilistic strength analysis of fibre bundle structures. Fibre Sci and Technol.1974;7:15-31.

[9] Phoenix SL. Probabilistic inter fiber dependence and the asymptotic strength distribution of classic fiber bundles. International Journal of Engineering Science.1975;13:287-304.

[10] Manders PW, Chou TW. Variability of carbon and glass fibres and the strength of aligned composites. J Reinf Plast Comp 1983;2:43-59.

[11] Chi Z, Wei Chou T, Shen G. Determination of single fiber strength distribution from fiber bundle testing. J Mater Sci 1984;19:3319-24.

[12] Evans KE, Cadduck BO, Ainsworth KL. Statistical change during the corrosion of glass fibre bundle J Mater Sci 1988;23:2926-2930.

[13] Cowking A, Attou A, Siddiki AM, Sweet MAS. Testing E-glass fibre bundle using acoustic emission J Mater Sci 1991;26:1301-1310.

[14] Okoroafor EU, Hill R. Relating acoustic emission signal parameters to the strength of fibres used in manufacture of polymeric composites. Ultrasonics 1995;33:123-131.

[15] Hill R, Okoroafor EU. Weibull statistics of fibre bundle failure using mechanical and acoustical emission testing: the influence of interfibre friction. Composites 1995;26:699-705.

[16] Okoroafor EU, Hill R. Investigation of complex failure modes in fibre bundles during dynamic mechanical testing using acoustic emission and Weibull statistics. J Mater Sci 1995;30:4233-4243.

[17] R'Mili M, Bouchaour T, Merle P. Estimation of Weibull parameters from loose bundle tests. Comp Sci and Tech 1996;56:831-834.

[18] R'Mili M, Murat M. Caractérisation des fibres par amélioration de l'essai sur mèche avec mesure directe de la déformation. CR. Acad Sci Paris, 1997;324(Iib):355-64.

[19] Lissart N, Lamon J. Evaluation des propriétés des monofilaments à partir d'essais de traction sur mèches. IN : Favre JP, Vautrin A, editors. Comptes rendus des $9^{\circ}$ Journées Nationales sur les composites (JNC9). AMAC; 1994 p. 589-598.

[20] Helmer T, Peterlik H, Kromp K. Coating of carbon fibers-The strength of the fibers. J Am Ceram Soc 1995;78:133-136.

[21] R'Mili M, Massardier V, Merle P, Vincent H, Vincent C. The effect of thermal exposure on the bundle strength distribution of B4C coated carbon fibers. Carbon 1999;37:129-145. 
[22] Beattie AG. Acoustic emission, principles and instrumentation. J acoustic emission 1983;2(1/2):95-128.

[23] Eitzen DG, Wadley HNG. Acoustic emission: establishing the fundamentals. J Res the Natl Bureau Stand 1984;89(1):75-100.

[24] Phoenix SL, Wu EM. Statistics for the time-Dependent Failure of Kevlar-49/Epoxy Composites: Micromechanical Modeling And Data Interpretation. UCRL-53365. Marsh 1983. LLNL, California.

[25] Hamstad MA, Moore RL. Acoustic emission from single and multiple Kevlar 49 filament breaks. J Comp Mater 1986;20:46-66.

[26] Calard V, Lamon J. Failure of fibre bundles. Comp Sci and Tech 2004;64:701-10.

[27] Creasy TS. A method of extracting Weibull survival model parameters from filament bundle load/strain data. Comp Sci and Tech 2000;60:825-832

[28] Hidalgo RC, Kun F, Herrmann JH. Bursts in a fiber bundle model with continuous damage, Phys rev 2001;64:0066122-30.

[29] Kun F, Zapperi S, Herrmann HJ. Damage in fiber bundle models, Eur. Phys. J. B. 2000;17:269-279.

[30] Brown EN, Davis AK, Jonnalagadda KD, Sottos NR. Effect of surface treatement on the hydrolytic stability of E-glass fiber bundle tensile strength. Comp Sci and Tech 2005;65:129136.

[31] Stoner EG, Edie DD, Durhan SD. An end-effect model fort he single filament tensile test. J Mater Sci 1994;29:6561-6574.

[32] Godin N, Huguet S, Gaertner R. Integration of the Kohonen's self-organising map and kmeans algorithm for the segmentation of the AE data collected during tensile tests on cross-ply composites. NDT \& E International 2005;38:299-309.

[33] Godin N, Huguet S, Gaertner R, Salmon L. Clustering of acoustic emission signals collected during tensile tests on unidirectionnal glass/polyester composites using supervised and unsupervised classifiers. NDT \& E International 2004;37:253-264.

[34] Huguet S, Godin N, Gaertner R, Use of acoustic emission to identify damage modes in glass fibre reinforced polyester. Comp Sci and Tech 2002;62:1433-1444.

[35] Gougeon N, Poulain M, El Abdi R. Evolution of strength silica optical fibers under various moisture condition. Optical Materials 2004;27:75-79. 
[36] Brown E. N, Davis A. K, Jonnalgadda K. D, Sottos N. R. Effect of surface treatment on the hydrolytic stability of E-glass fiber bundle tensile strength. Comp Sci and Tech 2005;65:129-136. 


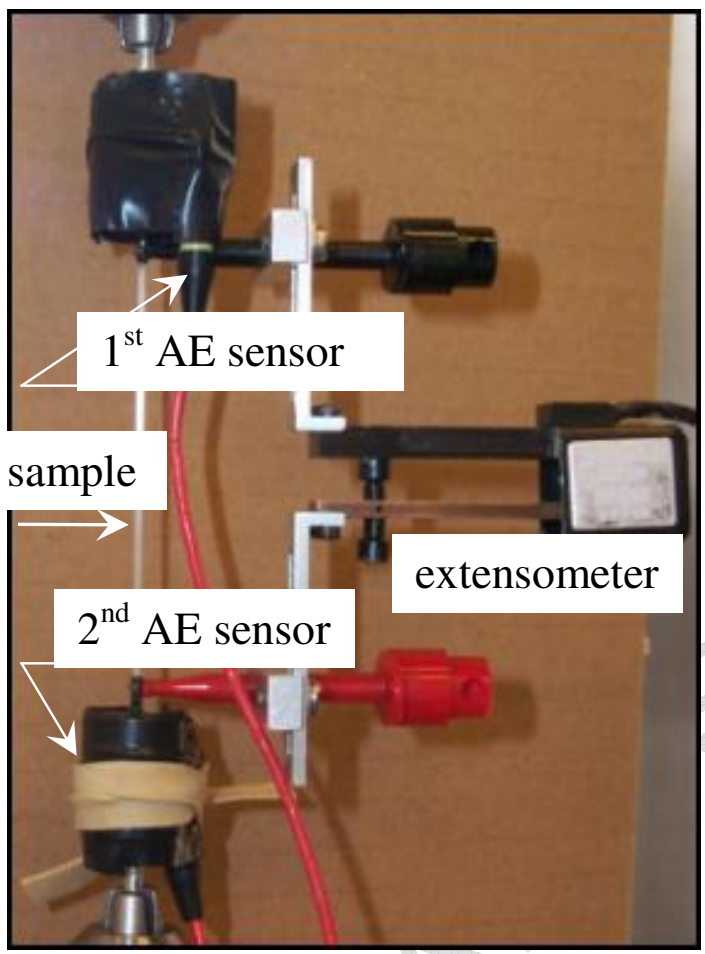

Fig.1. View of the experimental device to test E-glass fibre bundle with AE monitoring.

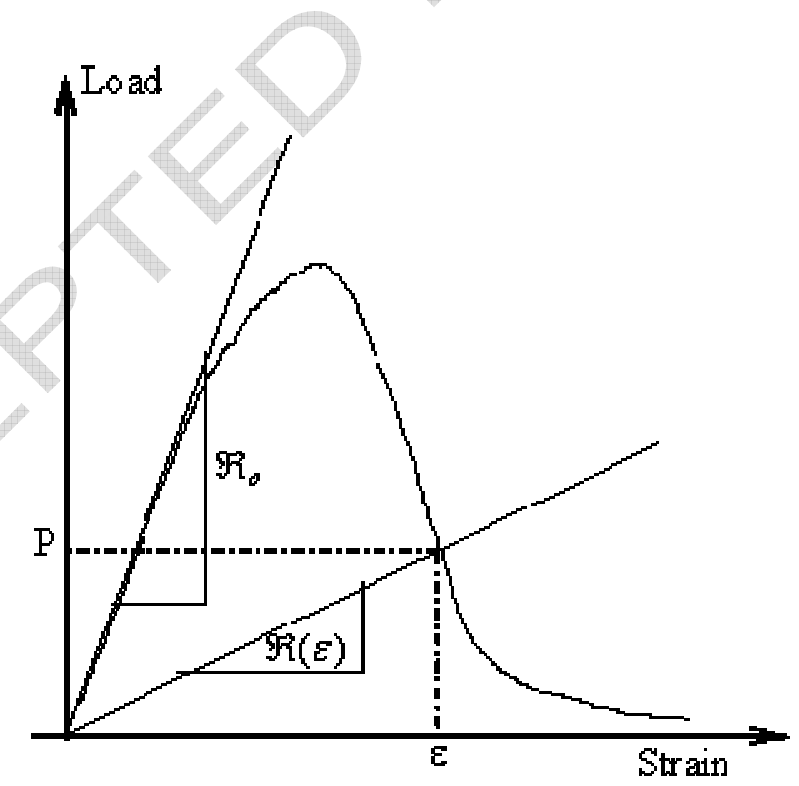

Fig.2. Typical method to evaluate $\mathfrak{R}_{\mathrm{o}}$ and $\mathfrak{R}(\varepsilon)$ from an experimental load-strain curve. 


\section{ACCEPTED MANUSCRIPT}

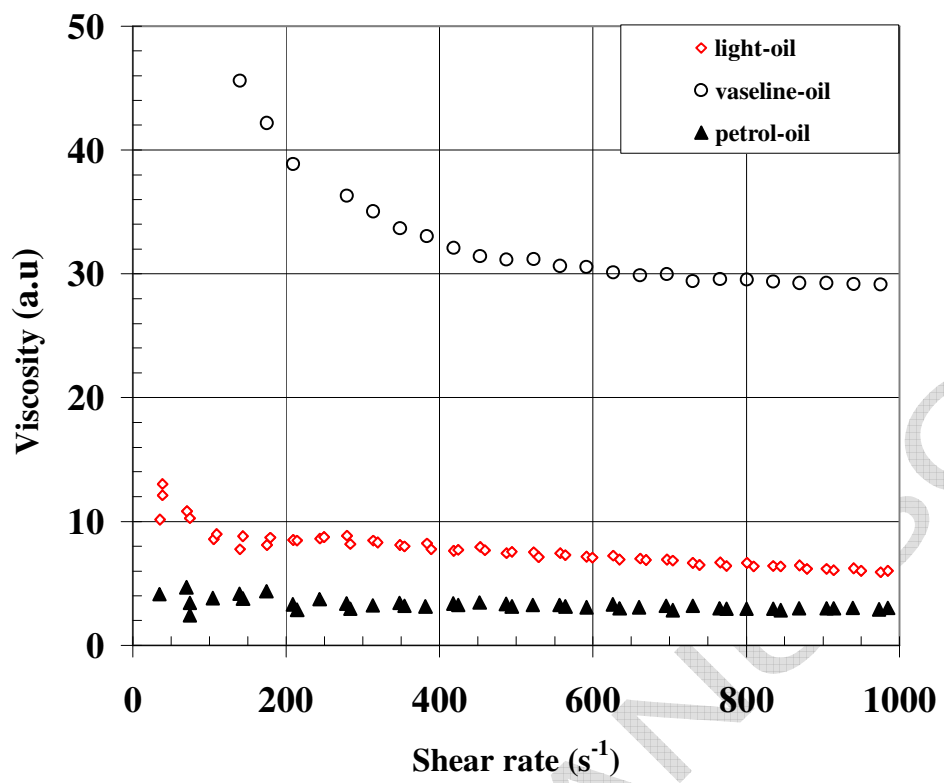

Fig.3. Effect of shear rate on viscosity for various lubricant oils.

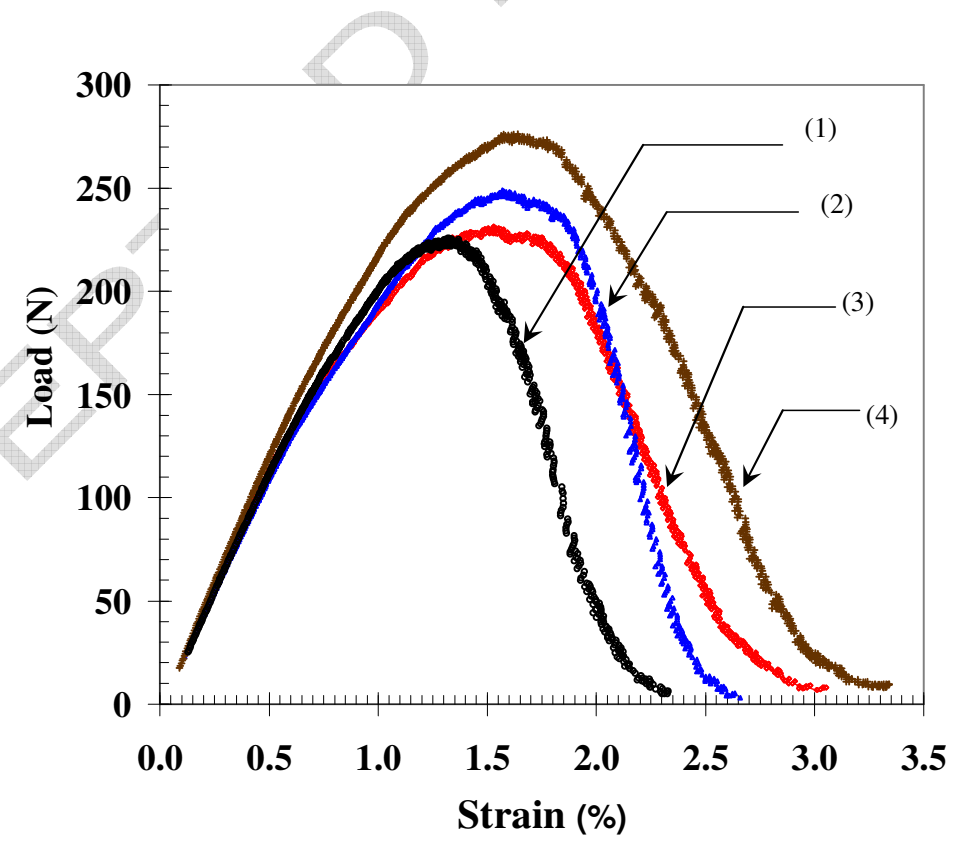

Fig.4. Effect of lubricant-oils on bundle fracture behaviour: Experimental load-strain curves for dry bundle (1), lubricated with petrol-oil (2), vaseline-oil (3) and light-oil (4) for $60 \mathrm{~mm}$ gauge length. 


\section{ACCEPTED MANUSCRIPT}

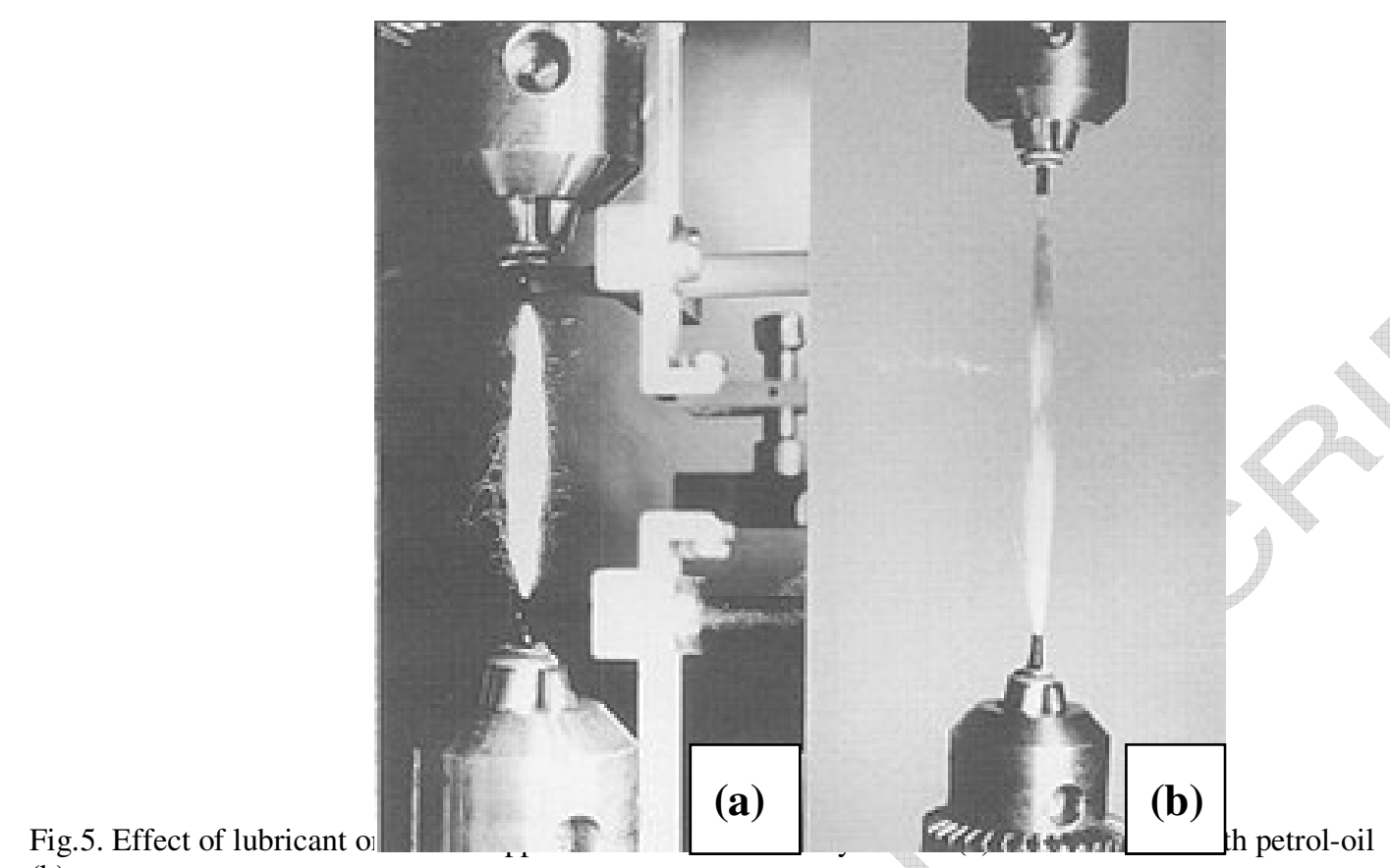

(b).

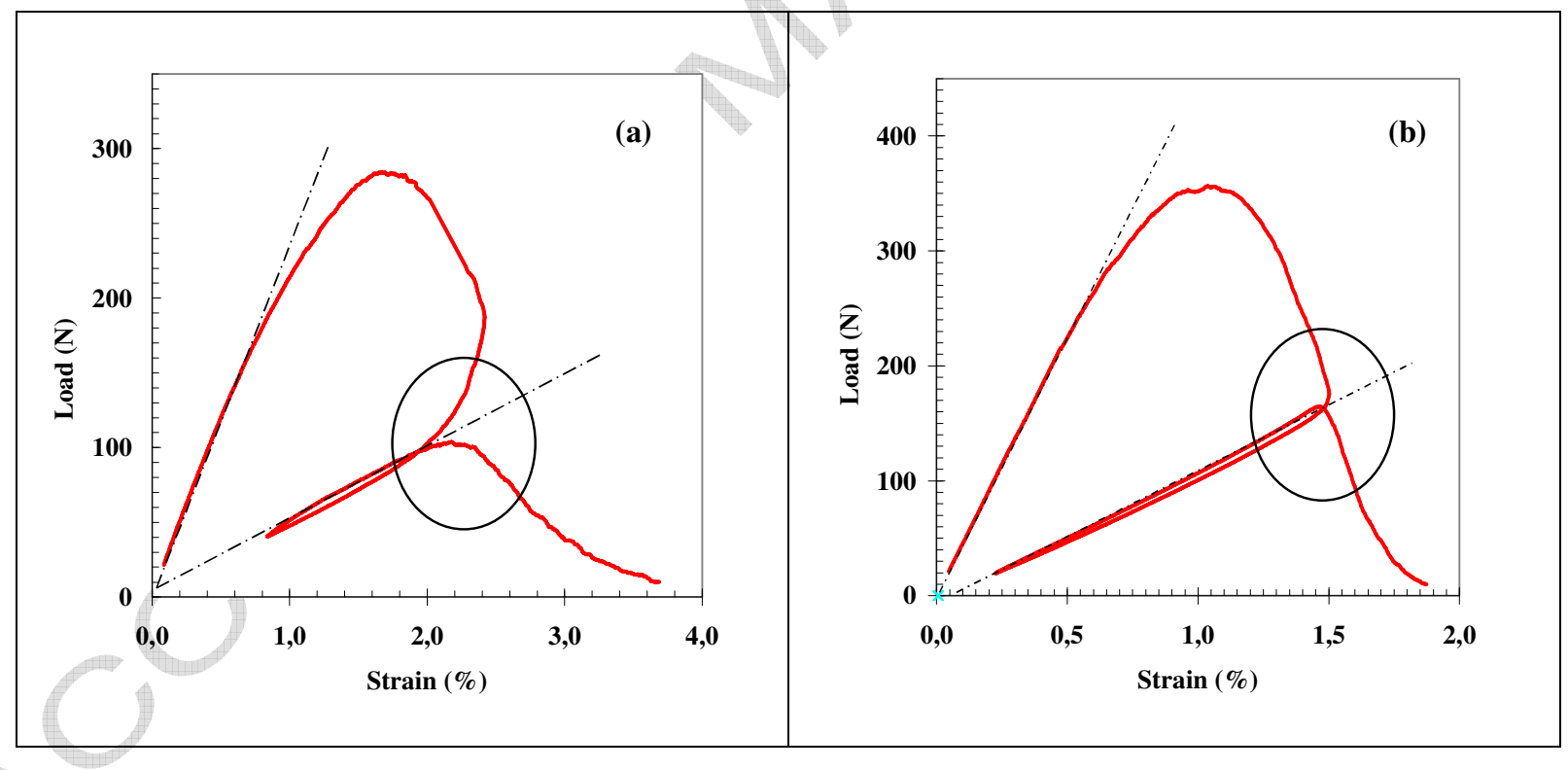

Fig.6. Typical load-strain curves with loading-unloading sequence for E-glass fibre (a) and carbon fibre (b), points out moisture effect on E-glass fibres. 


\section{ACCEPTED MANUSCRIPT}

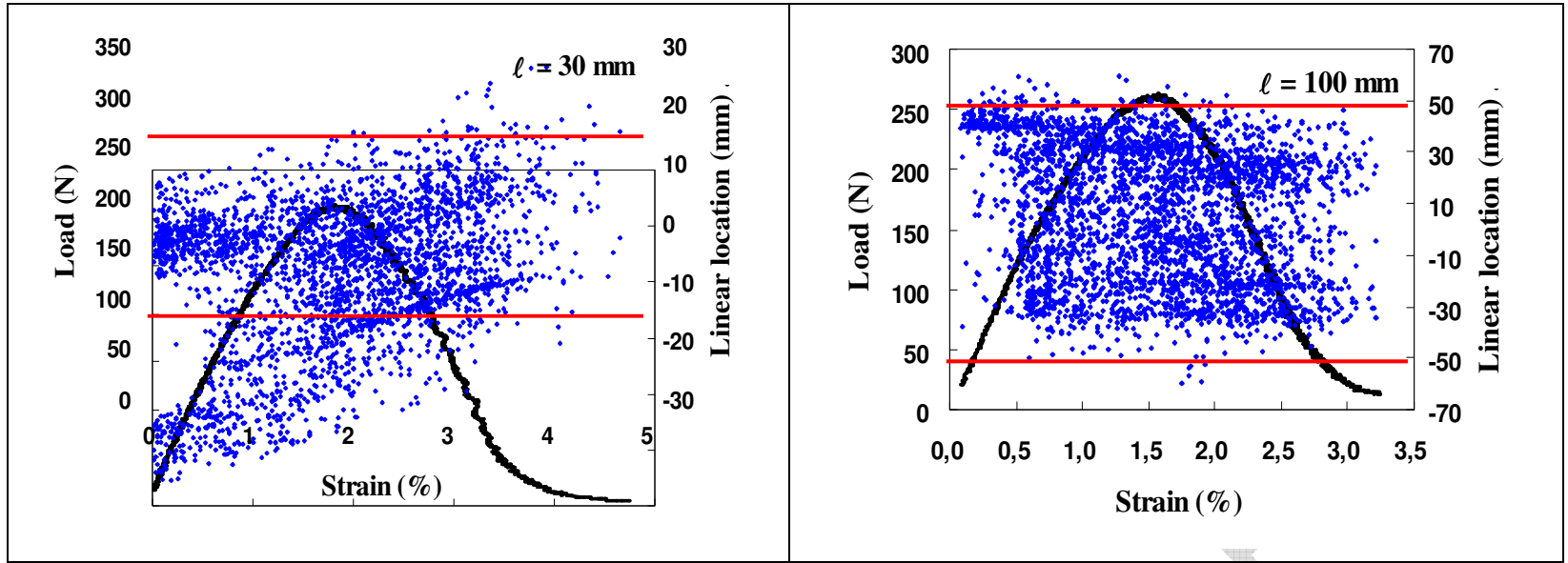

Fig.7. $P-\mathcal{E}$ curve and linear location of the events (fibre breaks) versus strain for tensile test for bundles with 30 and $100 \mathrm{~mm}$ gauge length (The solid lines indicate the approximate location of the bundle ends).
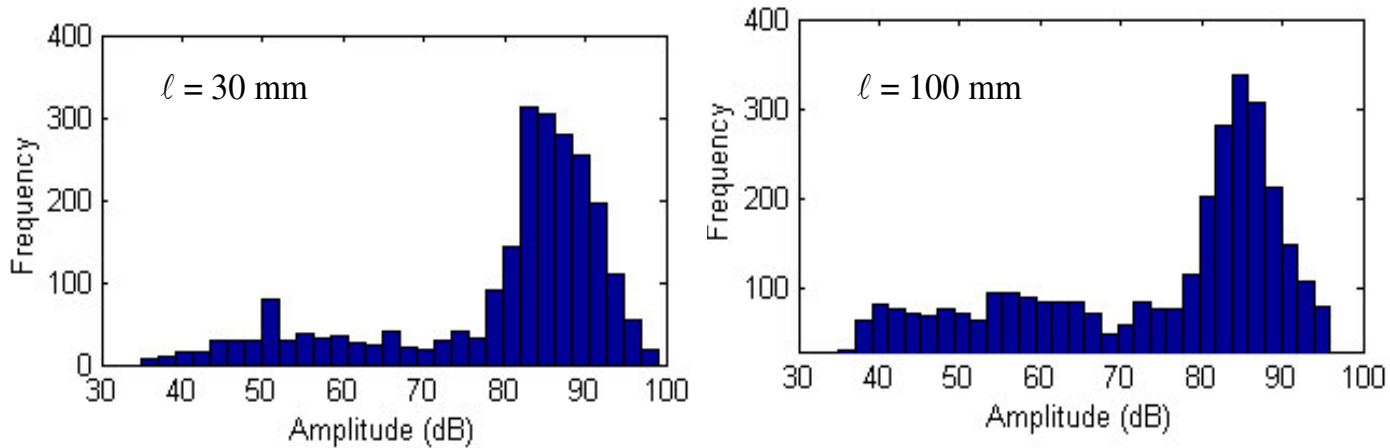

Fig.8. Amplitude distribution for bundle with 30 and $100 \mathrm{~mm}$ gauge length. 

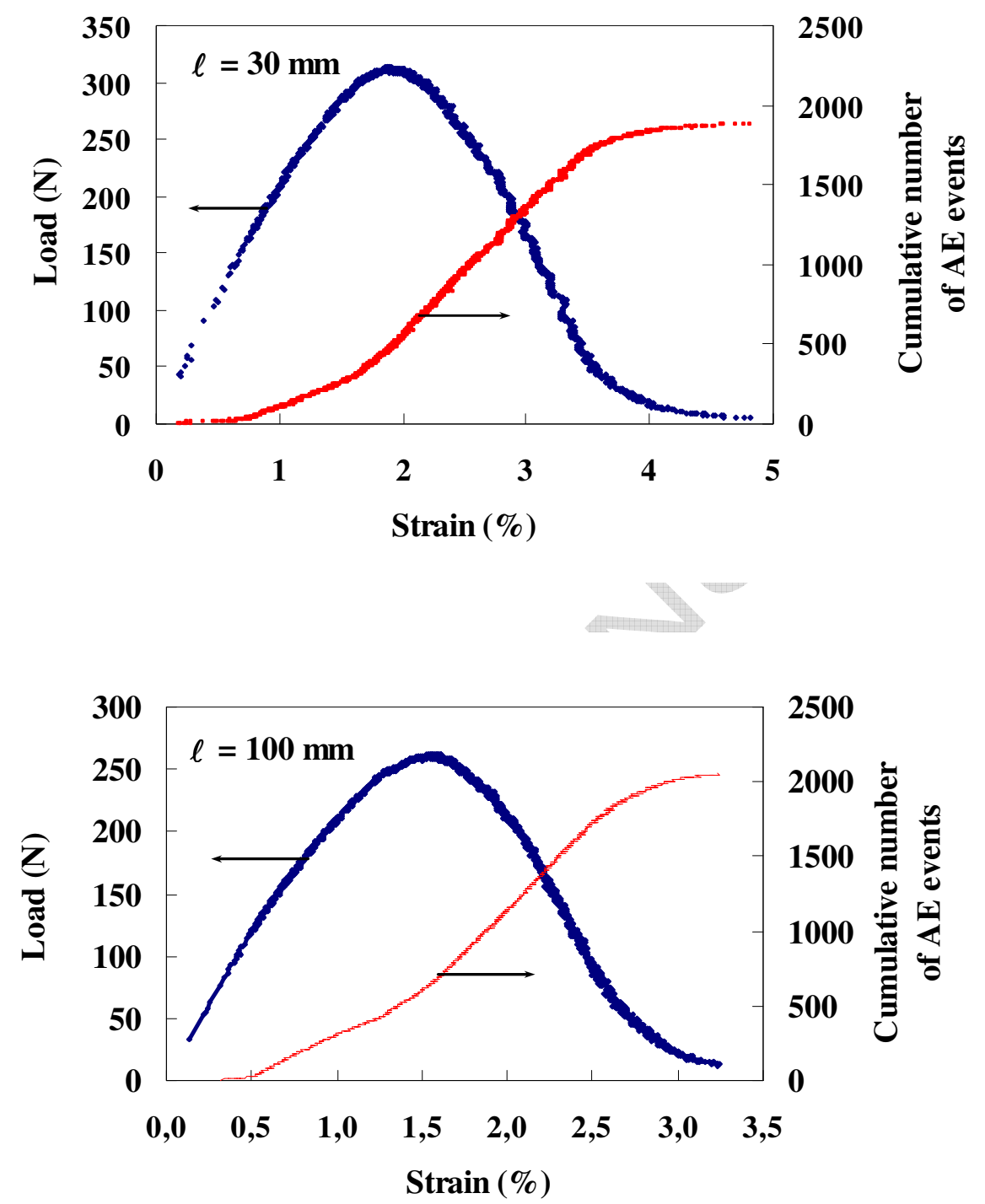

Fig.9. AE cumulative counts and load variations with applied strain for bundle with 30 and $100 \mathrm{~mm}$ gauge length. 


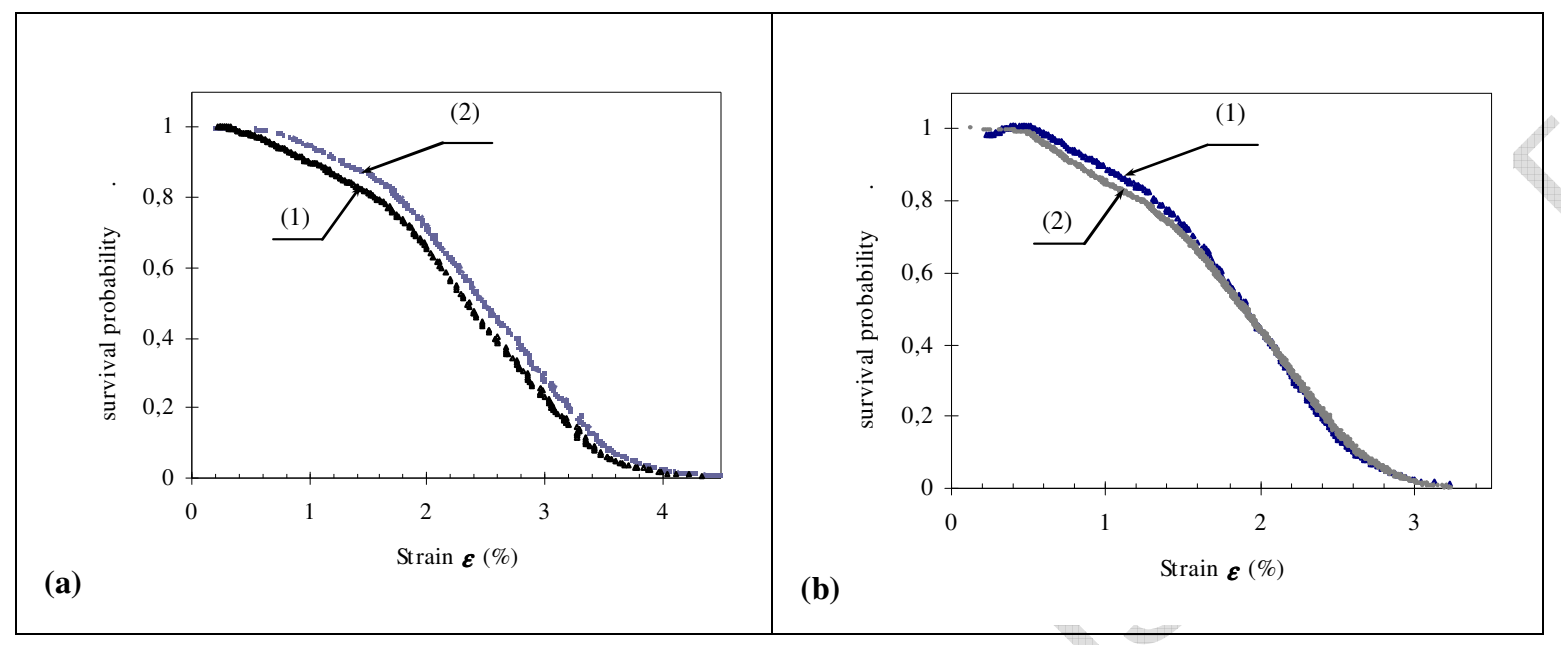

Fig.10. Comparison between the experimental survival probabilities obtained from $(P-\mathcal{E})$ (1) and AE (2) analysis for $30 \mathrm{~mm}$ (a) and $100 \mathrm{~mm}$ (b) gauge length.

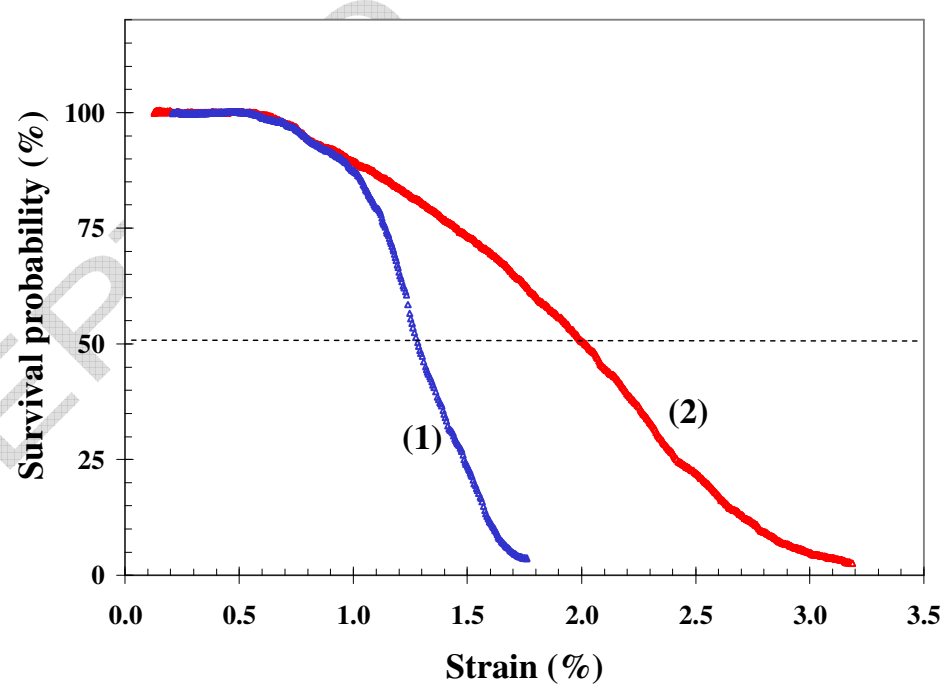

Fig.11. Moisture effect on fracture behaviour of bundles: Experimental load-strain curves for bundles wetted with water (1) and for bundle wetted with petrol oil (2) obtained for a $60 \mathrm{~mm}$ gauge length. 


\section{ACCEPTED MANUSCRIPT}

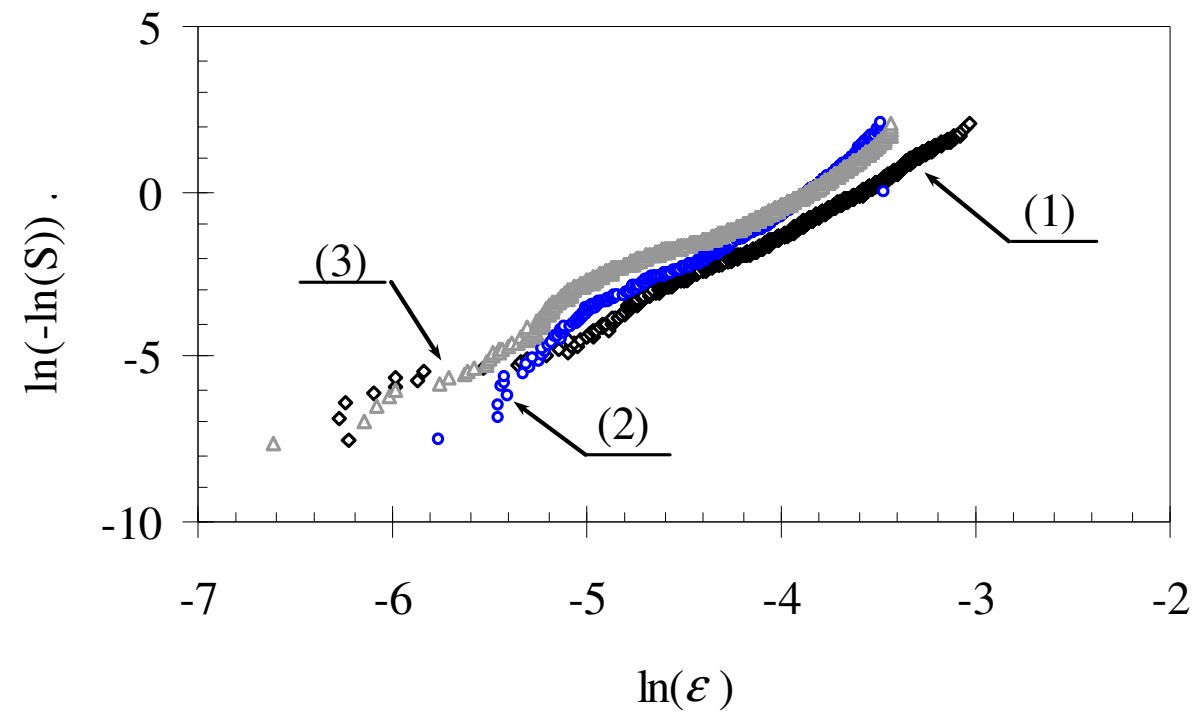

Fig.12. Experimental survival probability in Weibull diagram for 30 (1), 60 (2) and $60 \mathrm{~mm}$ (3) gauge lengths. 


\begin{tabular}{|c|c|}
\hline Sampling rate & $8 \mathrm{MHz}$ \\
\hline Preamplifier gain & $40 \mathrm{~dB}$ \\
\hline Threshold of detection & $32 \mathrm{~dB}$ \\
\hline Type of sensor & Micro-80 PAC \\
\hline Coupling & Silicon grease \\
\hline $\begin{array}{c}\text { Peak definition time } \\
\text { (PDT) }\end{array}$ & $50 \mu \mathrm{s}$ \\
\hline $\begin{array}{c}\text { Hit definition time } \\
\text { (HDT) }\end{array}$ & $100 \mu \mathrm{s}$ \\
\hline $\begin{array}{c}\text { Hit lockout time } \\
\text { (HLT) }\end{array}$ & $300 \mu \mathrm{s}$ \\
\hline Wave velocity & $3500 \mathrm{~m} / \mathrm{s}$ \\
\hline
\end{tabular}

Table 1: Typical setting of AE acquisition system

\begin{tabular}{|c|c|c|c|c|c|}
\hline \multirow{2}{*}{} & & \multicolumn{2}{|c|}{$\begin{array}{c}\text { Linear fit } \\
\text { Eq. (4) }\end{array}$} & \multicolumn{2}{c|}{$\begin{array}{c}\text { Non-linear fit } \\
\text { Eq. (3) }\end{array}$} \\
\hline$\ell(\mathrm{mm})$ & $N$ & $m$ & $\mathcal{E}(\%)$ & $m$ & $\mathcal{E}(\%)$ \\
\hline 30 & 1878 & 3.0 & 2.76 & 3.3 & 2.77 \\
& $(2086)$ & $(2.5)$ & $(2.63)$ & $(2.9)$ & $(2.61)$ \\
\hline 60 & 1949 & 3.6 & 2.14 & 4.0 & 2.15 \\
& $(1947)$ & $(4.7)$ & $(2.15)$ & $(4.6)$ & $(2.17)$ \\
\hline 100 & 2051 & 2.8 & 2.07 & 3.1 & 2.10 \\
& $(2085)$ & $(3.3)$ & $(2.06)$ & $(3.4)$ & $(2.10)$ \\
\hline
\end{tabular}

() Weibull parameters obtained by the $(P-\varepsilon)$ analysis.

Table 2: Weibull parameters obtained by linear method and the non-linear fit. Comparison between the $\mathrm{AE}$ and the $(P-\varepsilon)$ analysis. 